\title{
Extreme leukocytosis and leukemoid reaction associated with the lung sarcomatoid carcinoma: an unusual case report
}

This article was published in the following Dove Press journal:

International Journal of General Medicine

23 December 2016

Number of times this article has been viewed

\section{Danyang Wang \\ Haiyan Zhang \\ Fengkuan Yu \\ Baijun Fang}

Department of Hematopathy, The Affiliated Cancer Hospital of Zhengzhou University, Zhengzhou, People's Republic of China
Correspondence: Baijun Fang Department of Hematopathy, The Affiliated Cancer Hospital of Zhengzhou University, Zhengzhou 450008, People's Republic of China

Email fdation@।26.com.cn
Purpose: To report a rare case of extreme leukocytosis and leukemoid reaction associated with lung sarcomatoid carcinoma (LSC) and increase people's awareness of the disease.

Patients and methods: A 58-year-old male patient was diagnosed with LSC; however, after the end of the second course of chemotherapy, his white blood cells increased gradually without fever or use of medications such as granulocyte colony-stimulating factor and steroids. A bone marrow biopsy then confirmed it to be a leukemoid reaction.

Results: The patient died of multiple organ failure 2 months after being diagnosed with leukocytosis.

Conclusion: LSC associated with leukemoid reaction is very rare and the prognosis is poor. When a patient's white blood cells are extremely elevated, we should think of the possible causes of the tumor itself and identify it with other diseases. However, more data and evidence are still needed to find an effective adjuvant therapy for these patients.

Keywords: lung sarcomatoid carcinoma, leukemoid reaction

\section{Introduction}

Lung sarcomatoid carcinomas (LSCs) are very rare, mostly reported in the form of case reports, and leukemoid reactions has rarely been described in patients with LSC, to the best of our knowledge. Meanwhile, the mechanism of leukocytosis is not very clear. Here, we discuss an unusual case of extreme leukocytosis and a leukemoid reaction associated with the LSC. We summarize the relevant reports, hoping to provide some help for other clinicians when they encounter similar disease or symptoms.

\section{Case presentation}

A 58-year-old male patient had symptoms of intermittent cough and hemoptysis with no incentives in June 2014, and accompanying chest tightness and shortness of breath. He was first admitted to a local hospital, where computed tomography of the chest showed a left lung mass, suggesting a probability of tuberculosis. Therefore, he was treated for tuberculosis, but had no significant relief of symptoms. He then visited our hospital, where he underwent computed tomography-guided biopsy; the pathology results showed poorly differentiated adenocarcinoma (left lung). $\mathrm{He}$ then underwent surgery for resection of the mass; pathological examination showed poorly differentiated peripheral pulmonary carcinoma with the tumor being composed of mononuclear and multinucleated tumor giant cells with significant atypia. 
Immunohistochemistry showed: creatine kinase $(\mathrm{CK})(-)$, P63 (-), thyroid transcription factor (TTF)-1 (-), CK18 (+), Napsin A (-), CK (+), vimentin (+), smooth muscle actin (SMA) $(-)$, desmin $(-)$, epidermal growth factor receptor (EGFR) (++), Ki-67 (+60\%), epithelial membrane antigen (EMA) (+); the consideration is sarcomatoid carcinoma (giant cell carcinoma). The patient received two courses of chemotherapy in our hospital after surgery, gemcitabine 1.4 D1 and 8 + cisplatin $30 \mathrm{mg} \mathrm{D1-4}$ and tolerated it well.

However, the patient's white blood cells (WBCs) increased gradually without fever or use of medications, such as granulocyte colony-stimulating factor (G-CSF) and steroids, after the end of the second course (Figure 1), and neutrophils accounted for $\sim 93 \%$. While his hemoglobin and platelets were within the normal range. We initially used antibiotics empirically, which was ineffective. Next, a bone marrow biopsy was performed; the results showed myeloid and erythroid focal hyperplasia and significant partial immature myeloid cell proliferation (Figure 2). Immunohistochemistry showed individual lymphocytes CD3 (+), individual lymphocytes CD20 (+), erythroid CD235a (+), megakaryocytes CD61 (+), CD34 (-), individual monocytes CD14 $(+)$, individual plasma cells CD138 (+), a large number of myeloid myeloperoxidase (MPO) (+) (Figure 3). Finally, the patient was diagnosed with leukocytosis, then he and his family refused further chemotherapy, so we put the patient on "hydroxyurea" to

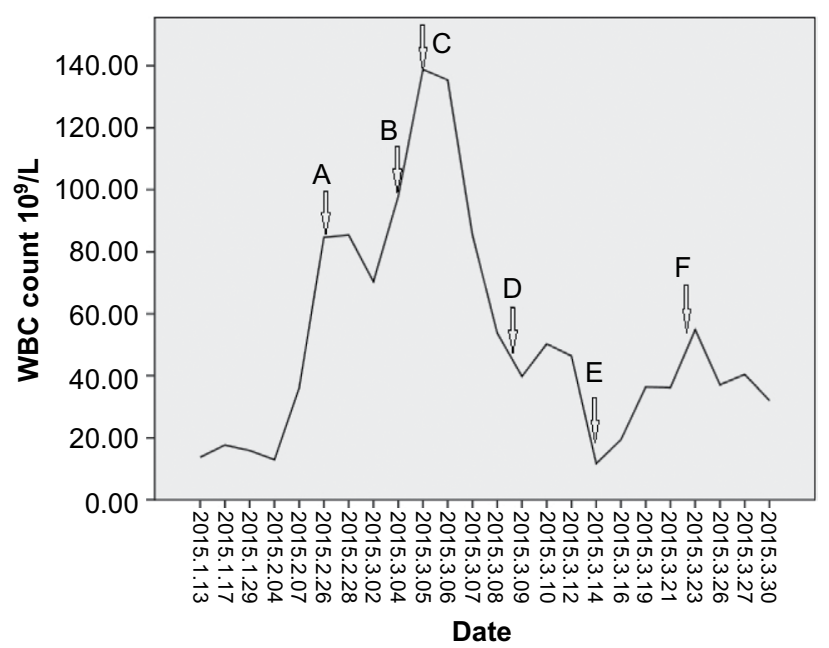

Figure I WBC gradually increased postoperatively.

Notes: "A" represents the day the patient took hydroxyurea $0.5 \mathrm{~g}$ tid po; "B" represents the day the patient took hydroxyurea $1.0 \mathrm{~g}$ tid po; " $\mathrm{C}$ " represents the day the patient took hydroxyurea $2.0 \mathrm{~g}$ bid po; " $D$ " represents the day the patient took hydroxyurea $1.0 \mathrm{~g}$ tid po; "E" represents the day the patient did not take the hydroxyurea; "F" represents the day the patient took hydroxyurea $1.0 \mathrm{~g}$ tid po. The patient was discharged on March 30, 2015.

Abbreviations: bid, twice daily; po, per os; tid, three times a day; WBC, white blood cell.

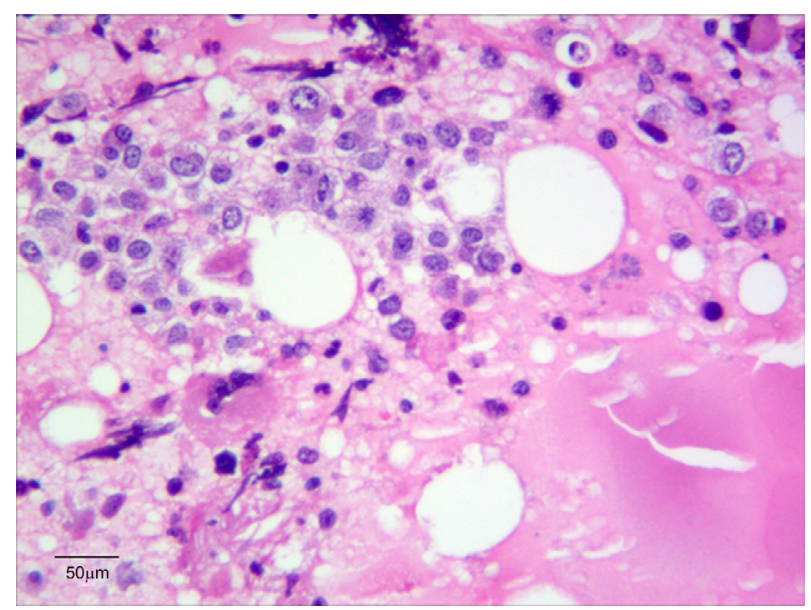

Figure 2 Bone marrow biopsy (hematoxylin and eosin $10 \times 40$ ).

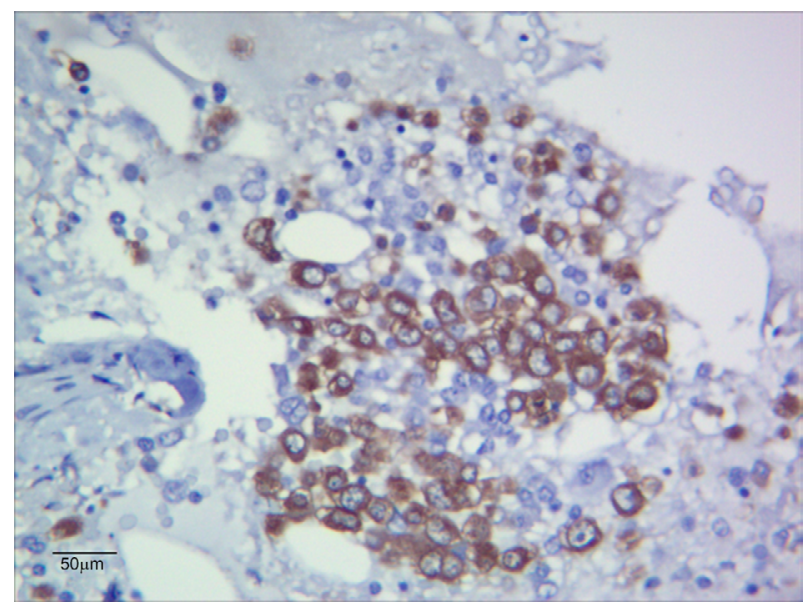

Figure 3 Immunohistochemistry (MPO 10×40).

Abbreviation: MPO, myeloperoxidase.

control the leukocytosis. The patient died of multiple organ failure 2 months after being diagnosed with leukocytosis. This study was approved by the Ethics Committee of The Affiliated Cancer Hospital of Zhengzhou University.

\section{Discussion}

Sarcomatoid carcinoma is a poorly differentiated malignant cancer, which is composed of both carcinomatous and sarcomatous elements. It can occur in many parts of the body, but most commonly affects the respiratory tract, lungs, breasts, and kidneys. Clinically, sarcomatoid carcinoma originating in the lung (LSC) is very rare, accounting for $0.3 \%-4.7 \%$ of all lung malignancies. ${ }^{1} \mathrm{LSC}$ is a non-small-cell lung carcinoma, which has a high degree of malignancy, and is more aggressive than the average lung cancers. The effects of radiotherapy and chemotherapy are not very good; therefore, the prognosis of LSC is poor. ${ }^{2-4}$ 
Leukemoid reaction is defined as a WBC count $>50 \times 10^{9} / \mathrm{L}$ without evidence of leukemia or infection. ${ }^{5}$ Leukemoid reaction is a potential cause for leukocytosis, especially in the presence of predominately mature granulocytic leukocytosis. A leukemoid reaction is caused by an exaggerated myeloid; it has been associated with infections, allergies, burns, intoxications, acute hemorrhage, malignant neoplasms, and several other stimuli. ${ }^{6-9}$

LSC associated with leukemoid reaction is very rare. The mechanism of leukemoid reaction is not very clear. Cancer-related symptoms, may be caused by G-CSF secreted by the tumor cells. ${ }^{10-12}$ Chen et al ${ }^{13}$ indicated that, in cases of leukemoid reaction, leukocytosis is frequently mediated by tumor-related cytokines and CSF including G-CSF, granulocyte-macrophage CSF, interleukin 6 or $1 \alpha$.

Jardin et $\mathrm{al}^{14}$ have reported a case with lung sarcoma and leukemoid reaction. The patient's G-CSF concentration increase was observed after the first cycle of chemotherapy $(>20,000 \mathrm{pg} / \mathrm{mL})$. Dramatically, the highest G-CSF concentration level was observed when the WBC count was lowest, suggesting that a massive cytokine release appeared after tumor lysis related to chemotherapy. ${ }^{14} \mathrm{We}$ also observed a similar phenomenon in our report; after chemotherapy, the patient's WBC experienced dramatic increases. For various reasons, we have not measured G-CSF concentration level, but we can speculate that perhaps the reason was the same.

Leukemoid reaction always indicates a high degree of malignancy, high probability of metastasis, and recurrence and wretched prognosis. In our report, the patient died of multiple organ failure 2 months after being diagnosed with leukocytosis. This is consistent with other reports correlating leukemoid reactions with advanced and aggressive tumor cell growth and poor outcome. ${ }^{6,15}$

In conclusion, LSC associated with leukemoid reaction is very rare and the prognosis is poor. When a patient's WBC is extremely elevated, we should think of possible causes of the tumor itself and identify it with other diseases. However, more data and evidence are still needed to find an effective adjuvant therapy for these patients.

\section{Acknowledgment}

Written informed consent was obtained from this patient for publication of this case report and any accompanying images.

\section{Disclosure}

The authors report no conflicts of interest in this work.

\section{References}

1. Pelosi G, Sonzogni A, De Pas T, et al. Pulmonary sarcomatoid carcinomas: a practical overview. Int J Surg Patho1. 2010;18(2):103-120.

2. Martin LW, Correa AM, Ordonez NG, et al. Sarcomatoid carcinoma of the lung: a predictor of poor prognosis. Ann Thorac Surg. 2007;84(3):973-980.

3. Venissac N, Pop D, Lassalle S, Berthier F, Hofman P, Mouroux J. Sarcomatoid lung cancel(spindle/giant cells): an aggressive disease? J Thorac Cardiovasc Surg. 2007;134(3):619-623.

4. Yuki T, Sakuma T, Ohbayashi C, et al. Pleomorphic carcinoma of the lung: a surgical outcome. J Thorac Cardiovasc Surg. 2007;134(2):399-404.

5. McKee L. Excess leukocytosis (leukemoid reactions) associated with malignant diseases. South Med J. 1985;78(12):1475-1482.

6. Stav K, Leibovici D, Siegel YI, Lindner A. Leukemoid reaction associated with transitional cell carcinoma. Isr Med Assoc J. 2002;4(3):223-224.

7. Marinella MA. Extreme leukemoid reaction associated with retroperitoneal hemorrhage. Arch Intern Med. 1998;158(3):300-301.

8. Pina-Ceballos VM, Montemayor-Garza R, Gonzalez-Oritz J. Leukemoid reaction secondary to prenatal use of betamethasone in a premature neonate. Rev Mex Pediatr. 1997;64:197-200.

9. Abramson N, Melton B. Leukocytosis: basics of clinical assessment Am Fam Physician. 2000;62(9):2053-2060.

10. Nimieri HS, Makoni SN, Madziwa FH, Nemiary DS. Leukemoid reaction response to chemotherapy and radiotherapy in a patient with cervical carcinoma. Ann Hematol. 2003;82(5):316-317.

11. Turalic H, Deamant FD, Reese JH. Paraneoplastic production of granulocyte colony-stimulating factor in a bladder carcinoma. Scand J Urol Nephrol. 2006;40(5):429-432.

12. Lee MY, Kaushansky K, Judkins SA, Lottsfeldt JL, Waheed A, Shadduck RK. Mechanism of tumor-induced neutroneutrophilia: constitutive production of colony-stimulating factors and their synergistic actions. Blood. 1989;74:115-122.

13. Chen YM, Whang-Peng J, Liu JM, et al. Leukemoid reaction resulting from multiple cytokine production in metastatic mucoepidermoid carcinoma with central necrosis. Jpn J Clin Oncol. 1995;25(4):168-172.

14. Jardin F, Vasse M, Debled M, et al. Paraneoplastic neutrophilic leukemoid reaction related to a G-CSF-secreting lung sarcoma. Am J Hematol. 2005;80(3):243-245.

15. Kasuga I, Makino S, Kiyokawa H, Katoh H, Ebihara Y, Ohyashiki K. Tumor-related leukocytosis is linked with poor prognosis in patients with lung carcinoma. Cancer. 2001;92(9):2399-2405.
International Journal of General Medicine

\section{Publish your work in this journal}

The International Journal of General Medicine is an international, peer-reviewed open-access journal that focuses on general and internal medicine, pathogenesis, epidemiology, diagnosis, monitoring and treatment protocols. The journal is characterized by the rapid reporting of reviews, original research and clinical studies across all disease areas.

\section{Dovepress}

The manuscript management system is completely online and includes a very quick and fair peer-review system, which is all easy to use. Visit http://www.dovepress.com/testimonials.php to read real quotes from published authors. 